\title{
Measurement and Management of Hyperlipidemia for the Primary Prevention of Coronary Heart Disease
}

Jack Froom, MD, Paul Froom, MD, Mignon Benjamin, MD, and Brian J. Benjamin, MD

Background: As part of the National Cholesterol Education Program (NCEP) two expert panel reports (1988, 1993) recommend serum cholesterol measurements in all adults aged 20 years and older and cholesterollowering treatment for those with abnormal levels.

Methods: All major drug intervention trials for primary prevention of coronary heart disease were reviewed. Similarly, selected studies on risks of dyslipidemia and benefit of therapy for the elderly and for women without coronary heart disease were analyzed. These studies were evaluated to test the soundness of the NCEP panel's recommendations.

Results and Conclusions: Five major randomized drug intervention trials for primary prevention of coronary heart disease showed that cholestyramine, gemfibrozil, clofibrate, and pravastatin can reduce the rate of nonfatal myocardial infarctions in middle-aged men. All-cause and ischemic heart disease mortality were increased by clofibrate and unaffected by the other three drugs. Extrapolation of these findings to women and older and younger men is unwarranted because there is no evidence that either diet or drugs provide primary protection from coronary heart disease in these groups. It is uncertain whether dyslipidemia is a risk factor for coronary heart disease in the elderly. The annual cost of drugs for full implementation of the panel's recommendations ranges from $\$ 6$ billion to $\$ 11.5$ billion and an additional $\$ 13$ billion will be required for initial screening, classifying, and monitoring serum cholesterol levels. Potential adverse consequences of a national program include possible risks from low cholesterol levels, drug side-effects, and disease labeling. (J Am Board Fam Pract 1998;11:12-22.)

In an attempt to reduce morbidity and mortality from coronary heart disease, the National Heart, Lung and Blood Institute initiated the National Cholesterol Education Program in November 1985. ${ }^{1}$ To support this program, they appointed an expert panel that in 1988 published specific guidelines for the classification and treatment of persons with elevated blood cholesterol levels. ${ }^{2}$

The expert panel recommended total serum cholesterol measurements in all adults aged 20 years and older and cholesterol-lowering treatment for persons whose low-density lipoprotein (LDL) cholesterol levels are $160 \mathrm{mg} / \mathrm{dL}$ or greater and for persons with coronary heart disease or two risk factors for cardiac disease whose LDL-cho-

Submitted, revised, 7 May 1997.

From the Department of Family Medicine, State University of New York at Stony Brook (JF), the Institute of Workers Health and Department of Epidemiology, Sackler School of Medicine, Tel Aviv University, Israel (PF), and the Department of Community and Family Medicine, Duke University, Durham, NC (MB, BJB). Address correspondence to Jack Froom, MD, Department of Family Medicine, State University of New York at Stony Brook, Stony Brook, NY $11794-6461$. lesterol levels equal or exceed $130 \mathrm{mg} / \mathrm{dL}$. They proposed dietary treatment initially, supplemented with drug therapy for persons who do not achieve the minimum goals after 6 months of intensive dietary therapy.

Several criticisms followed publication of the expert panel's population approach to primary prevention. These criticisms focused on costs of national screening, ${ }^{3-6}$ risk-benefit ratios of diagnosis and treatment interventions, ${ }^{7-10}$ increased workload for busy primary care physicians, ${ }^{6}$ the prevailing inaccuracy of blood cholesterol testing $^{11-13}$ and extrapolation of results of clinical trials in middle-aged men to women ${ }^{14-16}$ and to young ${ }^{14,17}$ and elderly men. ${ }^{14,18,19}$ Some expressed concern about the apparent poor prognosis of persons with low blood cholesterol levels. ${ }^{17}$ Others pointed out that in major trials, ${ }^{20-29}$ lowering blood cholesterol levels did not reduce all-cause mortality in persons without heart disease. A second report of the expert panel, published in 1993, amended recommendations of the first report and responded to some of the criticisms. ${ }^{30}$

The essential features of the second report of 
the expert panel are similar to those of the first report. The panel suggested that total serum cholesterol be measured in all adults aged 20 years and older. Treatment recommendations were linked to levels of serum cholesterol similar to those suggested in the first report. A few changes distinguish the second report from the first; these changes include recommendations for more intensive treatment and lower targets of LDL-cholesterol levels for patients with existing coronary heart disease. Less intensive treatment was suggested for most young adult men (younger than 35 years) and for premenopausal women with LDL-cholesterol levels in the range of 160-220 $\mathrm{mg} / \mathrm{dL}$. They added age as a major risk factor for coronary heart disease and suggested a somewhat more aggressive approach to treatment of highrisk postmenopausal women and asymptomatic elderly patients. Increased emphasis was given to high-density lipoprotein (HDL) blood levels (now added to the initial cholesterol testing and designated as a negative risk factor), and to weight loss and physical activity as components of dietary therapy. In operational terms the public health recommendations for primary prevention remained unchanged in that all adult patients are tested and classified by lipoprotein status, but with an expanded test profile. The only major change in treatment recommendations was delay of drug therapy in young adults until LDL-cholesterol levels exceed $220 \mathrm{mg} / \mathrm{dL}$.

This article is a critical review of the National Cholesterol Education Program's current recommendations for the primary prevention of coronary heart disease. A complete review of the literature for each of the following sections is beyond the scope of this report. Instead, we reviewed the major studies. For controversial issues we chose a sufficient number of studies to define the controversy, while attempting to avoid preferential citation of trials that support a particular position. ${ }^{31}$

\section{Issues Related to Primary Prevention Effectiveness of Cbolesterol-Lowering Measures}

There have been five major randomized, blinded, placebo-controlled, drug intervention trials for the primary prevention of coronary heart disease. ${ }^{20-29}$ Results of these studies are summarized in Table 1. The first is a report from Finland, ${ }^{20-23}$ a randomized, multifactorial primary prevention trial for vascular diseases, hyperlipidemia, hyper- tension, smoking, obesity, and abnormal glucose tolerance. A group of 612 high-risk men whose conditions were treated with diet, hypolipidemic drugs (mainly probucol and clofibrate), and antihypertensive drugs (mainly diuretics and $\beta$-blockers) were compared with 610 matched, high-risk men and 593 low-risk men who were not offered treatment. High-risk men had at least one of the following risk factors measured twice in consecutive tests: serum cholesterol levels of $270 \mathrm{mg} / \mathrm{dL}$ or higher, serum triglyceride levels of $149 \mathrm{mg} / \mathrm{dL}$ or higher, systolic blood pressure $160 \mathrm{mmHg}$ or higher, diastolic blood pressure $95 \mathrm{mmHg}$ or higher, smoking more than 10 cigarettes per day, 120 percent or more relative body weight, and a 1 hour glucose tolerance test reading of $162 \mathrm{mg} / \mathrm{dL}$ or more.

Within a 5-year period all risk factors were significantly reduced in the treated group when compared with the high-risk control group. Serum cholesterol levels in the high-risk intervention group fell from 275 to $259 \mathrm{mg} / \mathrm{dL}(P<0.001)$ but rose in the high-risk control group to $278 \mathrm{mg} / \mathrm{dL}$. Occurrence of stroke was significantly reduced in the intervention group when compared with the high-risk control group. Cardiac and all-cause mortality, as well as nonfatal myocardial infarction rates, were all higher in the intervention group than in either the high- or low-risk control groups, but these differences were not statistically significant.

At an 11-year follow-up review, all-cause mortality in the intervention group was significantly higher than in the high-risk control group (4.9 percent versus 3.9 percent, $P<0.04$ ) and in the low-risk group (1.8 percent, $P<0.03$ ). Although the difference in cardiovascular deaths between the high-risk groups was not significant at 11 years, it reached significance at 15 years $(5.6$ percent versus 2.3 percent, $P=0.001$ ). Neither multiple logistic regression analysis of confounding factors nor the accompanying editorial provided a "logical, scientifically convincing explanation" for excess mortality in the group that received the intensive intervention. 23

The largest double-blind drug intervention trial is a World Health Organization study of clofibrate compared with placebo. ${ }^{24-26}$ In this collaborative study 15,745 men aged 32 to 59 years at entry were divided into three groups and observed for an average of 5.3 years. Group 1, chosen at 
Table 1. Primary Prevention Trials.

\begin{tabular}{|c|c|c|c|c|c|c|c|}
\hline Trial & $\begin{array}{l}\text { Year Cohort } \\
\text { Enrollment } \\
\text { Began }\end{array}$ & Intervention & $\begin{array}{l}\text { Partici- } \\
\text { pants } \\
\text { (No.) }\end{array}$ & $\begin{array}{l}\text { Follow- } \\
\text { up } \\
\text { (y) }\end{array}$ & $\begin{array}{c}\text { Nonfatal } \\
\text { MIs } \\
\text { RR (95\% CI) }\end{array}$ & $\begin{array}{c}\text { All-cause } \\
\text { CHD Deaths } \\
\text { RR }(95 \% \text { CI) }\end{array}$ & $\begin{array}{c}\text { Deaths } \\
\text { RR ( } 95 \% \mathrm{Cl})\end{array}$ \\
\hline Finland $^{22}$ & 1972 & $\begin{array}{l}\text { Clofibrate or } \\
\text { probucol \& } \\
\text { multiple risk } \\
\text { factors }\end{array}$ & 1222 & 5.0 & $\begin{array}{c}1.9 \\
(0.8-4.4)\end{array}$ & $\begin{array}{c}4.0 \\
(0.5-36)\end{array}$ & $\begin{array}{c}2.0 \\
(0.7-5.8)\end{array}$ \\
\hline $\mathrm{WHO}^{26}$ & 1965 & Clofibrate & 10627 & 5.3 & $\begin{array}{c}0.75^{\star} \\
(0.6-0.9)\end{array}$ & $\begin{array}{c}1.1 \\
(0.7-1.7)\end{array}$ & $\begin{array}{c}1.3 \dagger \\
(1.0-1.6)\end{array}$ \\
\hline Helsinki ${ }^{27}$ & 1980 & $\begin{array}{l}\text { Gemfibrozil } \\
\text { and diet }\end{array}$ & 4081 & 5.0 & $\begin{array}{c}0.63 \dagger \\
(0.4-0.9)\end{array}$ & $\begin{array}{c}0.84 \\
(0.4-1.9)\end{array}$ & $\begin{array}{c}1.1 \\
(0.7-1.6)\end{array}$ \\
\hline LRC-CPPT ${ }^{28}$ & 1973 & $\begin{array}{l}\text { Cholestyramine } \\
\text { and diet }\end{array}$ & 3806 & 7.4 & $\begin{array}{c}0.82 \ddagger \\
(0.7-1.0)\end{array}$ & $\begin{array}{c}0.79 \\
(0.5-1.3)\end{array}$ & $(0.7-1.3)$ \\
\hline Scotland ${ }^{29}$ & 1989 & $\begin{array}{l}\text { Pravastatin } \\
\text { and diet }\end{array}$ & 6595 & 4.9 & $\begin{array}{c}0.70 \$ \\
(0.6-0.9)\end{array}$ & $\begin{array}{c}0.73 \\
(0.5-1.1)\end{array}$ & $\begin{array}{c}0.8 \\
(0.6-1.0)\end{array}$ \\
\hline
\end{tabular}

MI - myocardial infarction, CHD - cardiovascular disease, $\mathrm{CI}$ - confidence interval, RR - relative risk.

${ }^{\star} P=0.01$.

$\dagger P=0.016$.

$\ddagger P=0.048$ - significant when combined with CHD deaths.

$\$ P=0.001$.

random, comprised one half of the men who tested in the upper third of serum cholesterol levels. Group 2 comprised the other half, and group 3 was randomly chosen from those with serum levels in the lower third. Group 1 men received clofibrate, and the other two groups were given olive oil capsules as placebo.

Cholesterol levels rose in the control groups but fell 9 percent in the clofibrate group. Nonfatal myocardial infarctions occurred in 4.6 percent of group 1 (clofibrate) men compared with 6.2 percent in group $2(P<0.05)$. Comparable figures for ischemic heart disease deaths were 1.3 percent and 1.2 percent for group 1 and group 2, respectively (not significant). All-cause mortality was significantly higher $(P<0.05)$ in the clofibrate group compared with the two placebo groups: 4.9 percent for group 1, 3.8 percent for group 2 and 2.9 percent for group 3 . The differences in mortality could not be explained by excess ischemic heart disease or accident and violent deaths, but occurred from other medical causes. The number of cholecystectomies was significantly increased in the treatment group as compared with the others: 2.1 percent for group 1, and 0.9 percent for groups 2 and $3(P<0.001)$.

The principal investigators subsequently reported a 9.6-year follow-up ${ }^{25}$ and published a final report with a mean observation period of $\mathbf{1 3 . 2}$ years. ${ }^{26}$ Death rate in the clofibrate-treated group continued to be significantly higher than in the other groups at 9.6 years $(P<0.01)$. In the final follow-up report the number of deaths in the clofibrate-treated group was no longer significantly different from those in the other groups.

The Helsinki Heart Study compared gemfibrozil with placebo in 4081 asymptomatic men aged 40 to 55 years with LDL levels that exceeded $199 \mathrm{mg} / \mathrm{dL} .{ }^{27}$ After 5 years, as compared with placebo, the gemfibrozil group had fewer nonfatal myocardial infarctions ( 2.19 versus 3.50 percent) and fewer fatal myocardial infarctions $(0.29$ versus 0.39 percent). When the two end-points were taken together, the reduction was statistically significant $(P<0.02)$. All-cause mortality was 2.19 percent in the gemfibrozil group compared with 2.07 percent in the placebo group. Significant and sustained reductions in total cholesterol and LDL levels of almost 9 percent were achieved in those taking gemfibrozil but were virtually unchanged in the control group. In the gemfibrozil group there were nonsignificant increases in gall bladder operations (18 versus 12 ), eye operations (17 versus 12 ), and cataract surgery (7 versus 3 ) and significantly more gastrointestinal operations $(81$ versus $53, P<0.02$ ) when compared with the control group.

The Lipid Research Clinics Coronary Primary Prevention Trial (LRC ${ }^{28}$ ) compared the effect of cholestyramine with placebo in 3806 men aged 35 
to 59 years whose serum cholesterol level after dietary intervention was at least $265 \mathrm{mg} / \mathrm{dL}$ and whose LDL-cholesterol level was at least 190 $\mathrm{mg} / \mathrm{dL}$. Dietary intervention was continued throughout the trial and initially achieved approximately 5 percent reduction in both total and LDL cholesterol levels in all participants. After 7 years, total and LDL cholesterol levels fell an additional 9 percent $(P<0.001)$ in the cholestyramine group but were unchanged in those given placebo. All-cause mortality was nearly identical in both groups (3.7 and 3.6 percent in the control and cholestyramine groups, respectively), although it was not considered a primary end point.

The major benefit for the group taking cholestyramine was an attributable risk reduction of 1.7 percent for definite myocardial infarctions. Statistical significance of $P=0.048$ was reached by adding reductions in proved myocardial infarction to deaths from coronary heart disease, since neither alone was significant. The nonsignificant decrease in coronary heart disease deaths $(0.4$ percent) was cited as a 24 percent reduction in relative risk. The cholestyramine-treated group had more gall bladder operations (36 versus 25 ) and more gastrointestinal malignancies ( 21 versus 11), although these differences were not statistically significant. The authors summarize the importance of their findings as follows:

These results could be narrowly interpreted to apply only to the use of bile acid sequestrants in middle-aged men with cholesterol levels above 265 $\mathrm{mg} / \mathrm{dL}$ (perhaps 1 to 2 million Americans). The trial's implications, however, could and should be extended to other age-groups and women and since cholesterol levels and CHD risk are continuous variables, to others with more modest elevations of cholesterol levels.

Strongest evidence of benefit for cholesterol lowering comes from a study from Scotland of 6595 men aged 45 to 64 years, randomized to receive pravastatin or placebo. During a 5-year period, the drug-treated group had average total cholesterol reductions of 26 percent and HDL cholesterol levels rose by 5 percent. Definite nonfatal myocardial infarctions had an absolute reduction of 2.4 percent $(P<0.001)$ and coronary heart disease deaths 0.5 percent $(P=0.13)$. All-cause mortality was also reduced in the group receiving drugs; 4.1 versus 3.2 percent $(P=0.054$, incor- rectly reported by the authors as 0.051 ). There were no significant differences between the placebo groups and treatment groups in withdrawal from the study or adverse effects. All subgroups appeared to benefit, although a reduction of 3.2 percent in the primary end point (nonfatal myocardial infarcts and deaths caused by coronary heart disease) in patients with preexisting heart disease did not reach statistical significance, probably because the number of events was too few. ${ }^{29}$

\section{Comment}

Data from these five major studies indicate that lowering cholesterol with cholestyramine, gemfibrozil, clofibrate, and pravastatin in middle-aged men reduces the rate of nonfatal myocardial infarctions (4 of 5 studies, significant reduction in $3)$. The absolute risk reduction is modest, with a 0.8 to 2.4 percent decrease during a 5.0 - to 7.4 year follow-up period. All-cause and ischemic heart disease mortality are not significantly reduced by cholestyramine or gemfibrozil and are increased by clofibrate. Although there were nonsignificant reductions in all-cause mortality, the reduction in deaths caused by coronary heart disease in the pravastatin study almost reached significance. Better results achieved with pravastatin compared with cholestyramine, gemfibrozil, and clofibrate could relate to its greater ability to lower cholesterol levels ( 26 percent versus 9 percent).

To conserve resources and prevent anxiety from disease labeling, risks and benefits should be discussed before obtaining a screening serum cholesterol test. Limiting screening to patients with diabetes mellitus or those with a family history of coronary heart disease or of type II hyperlipidemia of Frederickson might also be prudent. If a dietary intervention fails, it might be reasonable to offer cholestyramine, gemfibrozil, or pravastatin to middle-aged men with elevated cholesterol levels (LDL cholesterol 130 to $159 \mathrm{mg} / \mathrm{dL}$ ) for primary prevention along with a full explanation of both benefits and adverse consequences of these drugs. Given the results from studies using clofibrate, few clinicians will use this drug. Although the cost of pravastatin is substantially higher than the other two drugs, its greater cholesterol-lowering effect and relative absence of reported adverse side effects will most likely make it the favored drug. 
Table 2. Cholesterol Levels and Risk of Cardiovascular Disease in the Elderly.

\begin{tabular}{|c|c|c|c|c|c|c|}
\hline Study & $\begin{array}{l}\text { Number of } \\
\text { Participants }\end{array}$ & $\begin{array}{c}\text { Age } \\
\text { (y) }\end{array}$ & $\begin{array}{c}\text { Follow-up } \\
\text { (y) }\end{array}$ & $\begin{array}{l}\text { Mortality, } \\
\text { All-cause }\end{array}$ & $\begin{array}{l}\text { Mortality, } \\
\text { CHD }\end{array}$ & $\begin{array}{l}\text { Nonfatal } \\
\text { MI }\end{array}$ \\
\hline Krumholz et al ${ }^{32}$ & 997 & $\geq 70$ & $\geq 4.0$ & NS & NS & NS \\
\hline Framingham ${ }^{18,19}$ & 5209 & $40-80$ & 30.0 & $\mathrm{NS}>50 \mathrm{y}$ & $N S>60 y$ & Not reported \\
\hline Bronx Aging ${ }^{33}$ & 350 & $75-85$ & 10.0 & $\begin{array}{c}\text { NS for TSC } \\
\text { Low HDL, men* }\end{array}$ & $\begin{array}{l}\text { NS for TSC } \\
\text { Low HDL, men }\end{array}$ & $\begin{array}{l}\text { NS for TSC } \\
\text { Low HDL, men }\end{array}$ \\
\hline Honolulu ${ }^{34}$ & 1480 & $65-74$ & 12.0 & Not reported & $\begin{array}{c}\text { Men with } \\
\text { nonfatal MI* }\end{array}$ & $\underset{\text { mortality }^{*}}{\text { Men with CHD }}$ \\
\hline Rubin et al ${ }^{35}$ & 2746 & $60-79$ & 10.1 & Not reported & $\operatorname{Men}^{*}$ & Not reported \\
\hline Barrett-Conner et al ${ }^{36}$ & 3187 & $50-79$ & $\geq 9.0$ & Men $50-64 y^{*}$ & $\begin{array}{c}\text { Men 50-64 } y^{*} \\
\text { Women 65-79 } y^{*}\end{array}$ & Not reported \\
\hline Aronow et a $\mathrm{l}^{37}$ & 708 & $62-103$ & $\geq 2.0$ & Not reported & $\begin{array}{l}\text { Nonfatal MI if } \\
\text { previous CHD* }\end{array}$ & $\begin{array}{l}\text { Nonfatal MI if } \\
\text { previous CHD* }\end{array}$ \\
\hline
\end{tabular}

CHD - coronary heart disease, MI - myocardial infarction, NS - not statistically significant, TSC - total serum cholesterol, HDL high-density lipoprotein.

*Statistically significant.

\section{Extrapolation to Other Groups}

It is helpful to explore whether the findings from these studies on primary prevention should be extrapolated to groups other than middle-aged men, as suggested by the authors of the Lipid Research Clinics study ${ }^{28}$ and advocated by the two expert panel reports. 2,30

\section{Age}

There are no studies on the use of medication to lower cholesterol for primary prevention of heart disease in the elderly or young adults. In the absence of such research, evidence as to whether hypercholesterolemia is a risk factor in these agegroups should be examined. There are at least 7 studies that address this issue for the elderly. Table 2 summarizes findings from these studies.

The most recent is an article by Krumholz and coworkers. ${ }^{32}$ They observed a community-based cohort of 997 persons older than 70 years for 4 years. When they compared persons having total serum cholesterol levels of $240 \mathrm{mg} / \mathrm{dL}$ or higher with those having cholesterol levels of less than $200 \mathrm{mg} / \mathrm{dL}$ and compared those in the lowest tertile of HDL cholesterol levels with those in the highest tertile, they found no significant differences in all-cause mortality, coronary heart disease mortality, or hospitalization for myocardial infarction or unstable angina. The sample size was sufficient for more than an 80 percent power to detect a relative risk of 1.6 in all-cause mortality for the highest serum cholesterol level group when com- pared with the lowest serum cholesterol level group. They concluded that neither hypercholesterolemia nor low HDL cholesterol levels are important risk factors in older persons.

These findings are in agreement with those reported from the Framingham Heart Study. In this study of 5209 men and women observed from 1948 through 1980, there were no significant relations between elevated serum cholesterol levels and all-cause mortality or coronary heart disease mortality in women aged 50 years and older and men aged 60 years and older. Above the age of 80 years the correlation was negative. The authors conclude that "at the present time there is no definitive basis for recommending lipid-lowering treatment in elderly men and women." 18,19

In the Bronx Aging Study, a 10-year prospective follow-up study of 350 persons aged 75 to 85 years, elevated total serum cholesterol level was not an independent risk factor for cardiovascular disease or all-cause mortality. Low HDL cholesterol levels, however, were significantly associated with myocardial infarction, cardiovascular disease, and all-cause mortality. In the multivariate analyses, previous myocardial infarction, diabetes, and hypertension at baseline were tested, but only hypertension was independently related to death in men. ${ }^{33}$

These data contrast with those reported by other investigators. The Honolulu Heart Program observed 1480 men aged 65 years and older for an average of 12 years. A comparison between 
subjects with upper and lower quartile serum cholesterol levels showed a statistically significant $(P=$ $0.006)$ increase in coronary heart disease rates for men in the highest quartile. ${ }^{34}$ The relative risk for elevated systolic blood pressure and a history of diabetes exceeded that of elevated total cholesterol but was less than that of number of cigarettes smoked daily. Similarly, Rubin and colleagues ${ }^{35}$ observed 2746 men aged 60 to 79 for approximately 10 years and found significantly more deaths from coronary heart disease in persons in the highest serum cholesterol quartile as compared with those in the lower three quartiles combined. This effect was independent after adjusting for age, systolic blood pressure, and smoking. Baseline data for these variables or for diabetes were not reported.

Barrett-Connor and colleagues ${ }^{36}$ observed a cohort of 3187 adults aged 50 to 79 for at least 9 years. In their study ischemic heart disease, but not all-cause mortality, was significantly correlated with elevated serum cholesterol levels in the group aged 65 to 79 years $(P<0.05)$. Cigarette smoking and hypertension were related to allcause but not ischemic heart disease mortality. Lastly, Aronow and colleagues ${ }^{37}$ reported data on 708 men and women with a mean age of $82 \pm 8$ years observed for $41 \pm 6$ months. Within that group for men and women with antecedent coronary artery disease, total serum cholesterol and HDL cholesterol levels were correlated with an increased risk for coronary events. Additional risk factors were age, previous coronary events, smoking, hypertension, and diabetes.

Both expert panels recommended testing and offering treatment to all persons aged 20 years and older. The initial expert panel's report notes, "There is little direct clinical trial evidence on whether elderly patients will benefit from intervention, and the strength of the association between LDL-cholesterol and CHD diminishes with age." They argue that there is some association between LDL-cholesterol levels and coronary heart disease, some evidence for effectiveness of interventions after myocardial infarction, and large potential benefits because of a high risk of coronary heart disease in the elderly. ${ }^{2}$

The second panel report ${ }^{30}$ noted that "Primary and secondary prevention clinical trials have included relatively few elderly patients and the question can be raised whether results carried out in middle-aged patients can be extrapolated to the elderly." They suggested that reduction of cardiovascular complications in elderly patients with systolic hypertension bolsters their argument that similar results can be expected from lowering cholesterol blood levels in older persons. The following quotes illustrate their position. "When faced with an older person with high serum cholesterol, the physician should maintain a positive attitude toward the potential benefits of cholesterol reduction." "There is no known reason why increased LDL levels per se will not promote coronary atherosclerosis in postmenopausal women as they do in men." "There are no data to preclude the use of cholesterol-lowering drugs for primary prevention in elderly patients on the basis of age alone."

\section{Comment}

Data from the studies quoted above indicate considerable uncertainty about whether an elevated serum cholesterol level is a risk factor for morbidity and mortality from coronary heart disease in the elderly. Lack of randomized clinical trials of cholesterol-lowering interventions in this agegroup suggests that such studies are needed before adopting recommendations of the National Cholesterol Education Program for both screening and management for primary prevention of heart disease in elderly persons.

\section{Sex}

Five of the 7 studies that examined the relation between hyperlipidemia and the risk of coronary events in the elderly involved both men and women. ${ }^{18,32,33,36,37}$ From these studies it is uncertain whether hyperlipidemia is a risk factor for cardiovascular and all-cause mortality and morbidity in elderly women who do not have a history of heart disease.

We found only one serum cholesterol-lowering drug trial for primary prevention of coronary heart disease that included women. ${ }^{38}$ This placebo-controlled study of colestipol hydrochloride tested its serum cholesterol-lowering ability and safety and included persons with and without preexisting coronary heart disease. Coronary heart disease deaths and all-cause mortality were significantly reduced in men younger than 50 years in the colestipol-treated group compared with those given placebo $(P<0.05)$. In contrast, there were no differences in mortality between the 
600 women given colestipol and a group of 583 who received placebo. A similar lack of effect on mortality from a cholesterol-lowering diet is reported in women given an institutional diet, although a favorable effect was reported in younger men. ${ }^{39}$

Ample documentation of differences in sex in the diagnosis, therapy, and prognosis of cardiovascular disease is given in an excellent review by Cole. ${ }^{40}$ Chest pain typical of angina predicts coronary artery disease in 72 percent of women compared with 93 percent of men. ${ }^{41}$ Similarly, in a group of middle-aged persons, there was a 67 percent false-positive rate for stress testing in women but only 8 percent in men, ${ }^{42}$ and breast tissue can interfere with the diagnostic accuracy of perfusion imaging. ${ }^{43,44}$

Women have more silent myocardial infarctions than men ${ }^{45,46}$ and a higher postinfarction mortality. ${ }^{47,48}$ The higher rates of mortality and morbidity subsequent to myocardial infarction in women compared with men cannot be fully explained by an older age at the time of myocardial infarction or a history of diabetes. ${ }^{49}$ Sex is also an independent risk factor for poorer outcome and increased mortality after percutaneous transluminal coronary angioplasty. ${ }^{50}$ Likewise, women have lower rates of success for coronary artery bypass surgery. ${ }^{51-53}$

Other differences in physiologic responses have been documented. Diets rich in monounsaturated fat or in (n-6)polyunsaturated fat are reported to be effective in lowering LDL cholesterol in men but not in women. ${ }^{54}$ In addition, there are sex differences in cardiac adaptation to essential hypertension, ${ }^{55}$ an increased mortality in women treated for hypertension compared with a decreased mortality in men, ${ }^{56}$ and even sex differences in cancer survival. ${ }^{57}$ In a review of research on the primary prevention of coronary heart disease in women, the authors note the absence of "definitive evidence that lowering cholesterol levels reduces the risk of coronary heart disease in healthy women," but suggest that data from observational studies indicate that such interventions might confer benefit. ${ }^{58}$ In contrast, a review by Walsh and Grady ${ }^{59}$ concludes, "There is no evidence that cholesterol lowering affects total mortality in healthy women, although the available data are limited."

The initial expert panel report ${ }^{2}$ pays little at- tention to sexual differences, except to note that older women have a higher prevalence of elevated blood cholesterol levels and lower rates of coronary heart disease than do men. The second expert panel report ${ }^{30}$ devotes considerable space to the issue of sex, best illustrated by the following quotes:

A primary issue, therefore, is how aggressively to treat elevated LDL-cholesterol levels in older women. There is no known reason why increased LDL levels per se will not promote coronary atherosclerosis in postmenopausal women as they do in men.... Nonetheless, it is inappropriate to ignore LDL-cholesterol levels in older women because they undoubtedly contribute to a rising risk for CHD.

For younger women, "dietary therapy, combined with weight reduction in the obese, and increased physical activity are indicated in women with high cholesterol levels, but a more cautious approach in the use of drugs is warranted for women compared to men of the same age."

\section{Comment}

The association between elevated blood cholesterol levels and increased risk for coronary heart disease morbidity and mortality in older women is uncertain, and no studies have been done that show benefit from lowering blood cholesterol for primary prevention in women of any age. There are marked differences in the manifestations of cardiovascular disease between men and women. "The assumption that cardiovascular disease, in terms of its risk factors, manifestations, and prognosis, is similar in women and men is no longer tenable." 60 It is difficult, therefore, to justify extrapolation of findings in middle-aged men to adult asymptomatic women of any age as suggested in both expert panel reports.

\section{Costs and Cost Effectiveness}

Cost effectiveness models for primary prevention are not instructive because they make assumptions that might be invalid. The models they use assume decreases in morbidity and mortality in groups for which randomized controlled trials of dietary and drug interventions are lacking, namely, women, the very young, and the elderly. Estimating costs per year of life saved by use of drugs for primary prevention in any age-group is unwarranted, $3,5,7,10,61$ because no studies have demon- 
strated a reduction in mortality. Furthermore, Johannesson et $a^{62}$ warn against extrapolation of cost-effectiveness findings from studies of patients with heart disease to primary prevention "in which the absolute risks of coronary heart disease are substantially lower." It may be more instructive, therefore, to focus only on costs.

On the basis of the expert panel's criteria, 2,30 52 million Americans have high serum cholesterol levels and are therefore candidates for dietary treatment. ${ }^{63}$ If cholesterol levels do not respond, the expert panels suggest combined diet and drug therapy, but measurement of LDL-cholesterol levels before starting drug therapy is recommended only for persons with borderline high blood cholesterol (200 to $239 \mathrm{mg} / \mathrm{dL}$ ) and HDLcholesterol levels of less than $35 \mathrm{mg} / \mathrm{dL}$, or with two or more risk factors. LDL-cholesterol level measurements are also recommended for those with high blood cholesterol $(240 \mathrm{mg} / \mathrm{dL}$ and above).

How likely is success for a population-based approach to cholesterol lowering by diet? Despite concerted efforts by every health promotion group, nutritional labeling on food packages, and an annual expenditure of $\$ 30$ billion for weight control, ${ }^{64}$ the prevalence of obesity in US adults increased from 25.4 percent in 1976-1980 to 33.3 percent in 1988-1991. Using a definition of body mass index of 27.8 and higher for men and 27.3 and higher for women, currently there are $58 \mathrm{mil}-$ lion overweight Americans. ${ }^{65}$

Sempos and colleagues ${ }^{63}$ estimate that $8.7 \mathrm{mil}$ lion persons ( 3.1 million aged 65 years or older) without established heart disease will require drug therapy. Most will receive an HMG-CoA reductase inhibitor such as lovastatin, which only 1 year after its introduction was the most frequently prescribed cholesterol-lowering drug. ${ }^{66}$ Pravastatin is the drug most likely to be chosen for primary prevention. Its retail annual cost at a local pharmacy for a $40-\mathrm{mg}$ daily dose is $\$ 1317.50$. Depending on daily dose (20 or $40 \mathrm{mg}$ ), annual costs for treating 8.7 million persons would range from $\$ 6$ billion to $\$ 11.5$ billion. These costs do not include initial screening, classification, and monitoring of cholesterol levels, which would add an additional $\$ 13$ billion for the first year of a national program. ${ }^{6}$ The workload for primary care physicians would be staggering, requiring 4300 extra office visits for each 1000 adult patients. ${ }^{6}$ Palumbo ${ }^{67}$ sums up the situation well with the comment, "at this point to avoid bankrupting our health care system and medical credibility, clinical judgment based on age, sex, family history and other risk factors must be emphasized as a necessary component of the NCEP [National Cholesterol Education Program] for individuals older than 60 years, and in fact, for those of all ages."

\section{Adverse Consequences}

The adverse consequences of a program for primary prevention of coronary heart disease by screening for and managing high blood cholesterol levels in asymptomatic persons have not been adequately studied. The increases in morbidity and mortality in those given medications compared with those given placebo are causes for concern. Pooled observational studies presented at a National Institutes of Health conference, ${ }^{68,69}$ "revealed highly significant associations between low levels of blood cholesterol (below 4.13 $\mathrm{mmol} / \mathrm{dL}$ ) and deaths from cancer, injuries, respiratory disease, gastrointestinal disease and other non-CHD causes." 69 In a meta-analysis assessing hazards of reducing serum cholesterol, Law et al ${ }^{70}$ found a significant relation with hemorrhagic stroke.

The adverse psychologic effects of disease labeling will likely cause the most widespread consequences. Although not reported specifically for hyperlipidemia, the phenomenon has been reported in such other health problems as hypertension, ${ }^{71}$ benign cardiac murmurs, ${ }^{72}$ and sickle cell trait. ${ }^{73}$ Other psychologic problems include depression, reported to be three times as frequent among men aged 70 years and older with low serum cholesterol levels (less than $160 \mathrm{mg} / \mathrm{dL}$ ). ${ }^{74}$

\section{Summary}

We limited our analysis to primary prevention for several reasons. In contrast to secondary prevention, the population contains a large subset for whom an intervention offers no potential benefit, and demonstration of benefit requires more subjects receiving treatment for a longer period. In addition, a recommendation for a screening test offered to a healthy person should be preceded by informed consent ${ }^{75}$ and requires substantially better evidence of benefit than one used for a patient with established disease. ${ }^{76}$

Although there is considerable documentation 
of a relation between dyslipidemia and risk of coronary heart disease, benefit from cholesterollowering measures, even when successful, is by no means assured. Evidence that coronary disease morbidity and mortality can be prevented is limited to middle-aged men, but all-cause mortality reduction has not been shown in this group. Extrapolation of findings from secondary prevention trials to patients without heart disease is unwarranted. There are conflicting data on the association between hyperlipidemia and coronary heart disease in the elderly, and no studies show benefit of interventions in women, the young, and the elderly. In addition, the lack of universally available accurate cholesterol tests and the potential risks of available interventions make a national program unattractive. In a climate of cost containment, the very large cost of testing and providing treatment for all adults aged 20 years and older requires careful scrutiny.

We have presented the data from the five major studies, four of which were available to the expert panel for its recommendations. With the possible exception of those for men aged 35 to 59 years, the findings do not seem to us to warrant the expenditure of tens of billions of dollars and the placing of millions of women and young and elderly men at risk for the consequences of disease labeling. The dangers of prolonged cholesterollowering therapy must also be considered, since there is much we do not know about the statins, and what we do know about some of the other drugs is profoundly disquieting.

\section{References}

1. Lenfant C. A new challenge for America: the National Cholesterol Education Program. Circulation 1986;73:855-6.

2. Report of the National Cholesterol Education Program Expert Panel on Detection, Evaluation, and Treatment of High Blood Cholesterol in Adults. The Expert Panel. Arch Intern Med 1988:148:36-69.

3. Kristiansen IS, Eggen AE, Thelle DS. Cost effectiveness of incremental programmes for lowering serum cholesterol concentration: is individual intervention worth while? BMJ 1991;302:1119-22.

4. Smith GD, Song F, Sheldon TA. Cholesterol lowering and mortality: the importance of considering initial level of risk. BMJ 1993;306:1367-73.

5. Goldman L, Weinstein MC, Goldman PA, Williams LW. Cost-effectiveness of HMG-CoA reductase inhibition for primary and secondary prevention of coronary heart disease. JAMA 1991;265:1145-51.

6. Froom J, Froom P. Consequences of the National
Cholesterol Education Program. J Fam Pract 1990; 30:533-6.

7. Krahn M, Naylor CD, Basinski AS, Detsky AS. Comparison of an aggressive (U.S.) and a less aggressive (Canadian) policy for cholesterol screening and treatment. Ann Intern Med 1991;115:248-55.

8. Feldman W. How serious are the adverse effects of screening? J Gen Intern Med 1990;5(5 Suppl):S50-3.

9. Kinlay S, Heller RF. Effectiveness and hazards of case finding for a high cholesterol concentration. BMJ 1990;300:1545-7.

10. Kinosian BP, Eisenberg JM. Cutting into cholesterol: cost-effective alternatives for treating hypercholesterolemia. JAMA 1988;259:2249-54.

11. Current status of blood cholesterol measurement in clinical laboratories in the United States: a report from the Laboratory Standardization Panel of the National Cholesterol Education Program. Bethesda, Md: National Institutes of Health, 1988. (NIH publication no. 88-2928.)

12. Kaufman HW, McNamara JR, Anderson KM, Wilson PW, Schaefer EJ. How reliably can compact chemistry analyzers measure lipids? JAMA 1990; 263:1245-9.

13. Naughton MJ, Luepker RV, Strickland D. The accuracy of portable cholesterol analyzers in public screening programs. JAMA 1990;263:1213-7.

14. Grundy SM. Cholesterol and coronary heart disease. Future directions. JAMA 1990;264:3053-9.

15. Bengtsson C, Bjorkelund C, Lapidus L, Lissner L. Associations of serum lipid concentrations and obesity with mortality in women: 20 year follow up of participants in prospective population study in Gothenburg, Sweden. BMJ 1993;307:1385-8.

16. Froom J, Froom P. "Prudence" in disease prevention. J Clin Epidemiol 1991;44:1127-30.

17. Hulley SB, Newman TB, Grady D, Garber AM, Baron RB, Browner WS. Should we be measuring blood cholesterol levels in young adults? JAMA 1993;269:1416-9.

18. Anderson KM, Castelli WP, Levy D. Cholesterol and mortality: 30 years of follow-up from the Framingham study. JAMA 1987;257:2176-80.

19. Kronmal RA, Cain KC, Ye Z, Omenn GS. Total serum cholesterol levels and mortality risk as a function of age. A report based on the Framingham data. Arch Intern Med 1993;153:1065-73.

20. Miettinen TA, Huttunen JK, Naukkarinen VA, Strandberg T, Mattila S, Kumlin T, et al. Multifactorial primary prevention of cardiovascular diseases in middle-aged men. Risk factor changes, incidence, and mortality. JAMA 1985;254:2097-102.

21. Naukkarinen VA, Strandberg TE, Vanhanen HT, Salomaa VV, Sarna SJ, Miettinen TA. Mortality rates after multifactorial primary prevention of cardiovascular diseases. Ann Med 1989;21:441-6.

22. Strandberg TE, Salomaa VV, Naukkarinen VA, Vanhanen HT, Sarna SJ, Miettinen TA. Long-term mortality after 5 -year multifactorial primary prevention of cardiovascular diseases in middle-aged men. 
JAMA 1991;266;1225-9.

23. Oglesby $\mathrm{P}$, Hennekens $\mathrm{CH}$. The latest report from Finland. A lesson in expectations. JAMA 1991;266: $1267-8$.

24. A co-operative trial in the primary prevention of ischaemic heart disease using clofibrate. Report from the Committee of Principal Investigators. Br Heart J 1978;40:1069-118.

25. WHO cooperative trial on primary prevention of ischaemic heart disease with clofibrate to lower serum cholesterol: mortality follow-up. Report of the Committee of Principal Investigators. Lancet 1980; 2:379-85.

26. WHO cooperative trial on primary prevention of ischaemic heart disease with clofibrate to lower serum cholesterol: Final mortality follow-up. Report of the Committee of Principal Investigators. Lancet 1984;2:600-4.

27. Frick MH, Elo O, Haapa K, Heinonen OP, Heinsalmi $P$, Helo $P$, et al. Helsinki Heart Study: primary prevention trial with gemfibrozil in middle-aged men with dyslipidemia. Safety of treatment, changes in risk factors and incidence of coronary heart disease. N Engl J Med 1987:317;1237-45.

28. Lipid Research Clinics Coronary Primary Prevention Trial results. I. Reduction in the incidence of coronary heart disease. JAMA 1984;251:351-64.

29. Shepherd J, Cobbe SM, Ford I, Isles CG, Lorimer AR, MacFarlane PW, et al. Prevention of coronary heart disease with pravastatin in men with hypercholesterolemia. West of Scotland Coronary Prevention Study Group. N Engl J Med 1995;333:1301-7.

30. Second report of the expert panel on detection, evaluation, and treatment of high blood cholesterol in adults (adult treatment panel II). Bethesda, $\mathrm{Md}: \mathrm{Na}-$ tional Cholesterol Education Program, National Institutes of Health, National Heart, Lung, and Blood Institute, 1993. (NIH publication no. 93-3096.)

31. Ravnskov U. Cholesterol lowering trials in coronary heart disease: frequency of citation and outcome. BMJ 1992;305:15-9.

32. Krumholz HM, Seeman TE, Merrill SS, Mendes de Leon CF, Vaccarino V, Silverman DI, et al. Lack of association between cholesterol and coronary heart disease mortality and morbidity and all-cause mortality in persons older than 70 years. JAMA 1994; 272:1335-40.

33. Zimetbaum P, Frishman WH, Ooi WL, Derman MP, Aronson M, Gidez LI, et al. Plasma lipids and lipoproteins and the incidence of cardiovascular disease in the very elderly. The Bronx Aging Study. Arterioscler Thromb 1992;12:416-23.

34. Benfante $R$, Reed $D$. Is elevated serum cholesterol a risk factor for coronary heart disease in the elderly? JAMA 1990;263:393-6.

35. Rubin SM, Sidney S, Black DM, Browner WS, Hulley SB, Cummings SR. High blood cholesterol in elderly men and the excess risk for coronary heart disease. Ann Intern Med 1990;113:916-20.

36. Barrett-Conner E, Suarez L, Khaw K, Criqui MH,
Wingard DL. Ischemic heart disease risk factors after age 50. J Chronic Dis 1984;37:903-8.

37. Aronow WS, Herzig AH, Etinene F, D'Alba P, Ronquillo J. 41-month follow-up of risk factors correlated with new coronary events in 708 elderly patients. J Am Geriatr Soc 1989;37:501-6.

38. Dorr AE, Gundersen $K$, Schneider JC Jr, Spencer TW, Martin WB. Colestipol hydrochloride in hypercholesterolemic patients-effect on serum cholesterol and mortality. J Chronic Dis 1978;31:5-14.

39. Frantz ID Jr, Dawson EA, Kuba K, Brewer ER, Gatewood LC, Bartsch GE. The Minnesota coronary survey: effect of diet on cardiovascular events and deaths. Circulation 1995;52(Suppl 2);II-4.

40. Cole PL. Coronary artery disease in women: differences in diagnosis, therapy, and prognosis. Coron Artery Dis 1993;4:595-604.

41. Chaitman BR, Bourassa MG, Davis K, Rogers WJ, Tyras DH, Berger R, et al. Angiographic prevalence of high-risk coronary artery disease in patient subsets (CASS). Circulation 1981;64:360-7.

42. Sketch MH, Mohiuddin SM, Lynch JD, Zencka AE, Runco V. Significant sex differences in the correlation of electrocardiographic exercise testing and coronary arteriograms. Am J Cardiol 1975;36:16973.

43. Wackers F. Diagnostic pitfalls of myocardial perfusion imaging in women. J Myocardial Imaging 1992;4:23-38.

44. Goodgold HM, Rehder JG, Samuels LD, Chairman BR. Improved interpretation of exercise T1-201 myocardial perfusion scintigraphy in women: characterization of breast attenuation artifacts. Radiology 1987;165:361-6.

45. Kannel WB, Sorlie P, McNamara PM. Prognosis after initial myocardial infarction: the Framingham study. Am J Cardiol 1979;44:53-9.

46. Kannel WB, Abbot RD. Incidence and prognosis of myocardial infarction in women: the Framingham study. In Wenger NK, editor. Coronary heart disease in women. New York: Haymarket-Doyma 1987:20814.

47. Becker R, Ross R, Terrin M, Knatterud G, Braunwald $E$, TLMI Investigators. Gender related differences in clinical outcome following acute MI (abstract). Circulation 1990;82:III-667.

48. Greenland P, Reicher-Reiss H, Goldbourt U, Behar S. In-hospital and 1-year mortality in 1,524 women after myocardial infarction. Comparison with 4,315 men. Circulation 1991;83:484-91.

49. Becker RC, Terrin M, Ross R, Knatterud GL, Desvigne-Nickens $\mathrm{P}$, Gore JM, et al. Comparison of clinical outcomes for women and men after acute myocardial infarction. The Thrombolysis in Myocardial Infarction Investigators. Ann Intern Med 1994;120: 638-45.

50. Cowley MJ, Mullin SM, Kelsey SF, Kent KM, Gruentzig AR, Detre KM, et al. Sex differences in early and long-term results of coronary angioplasty in the NHLBI PTCA Registry. Circulation 1985;71:90-7. 
51. Douglas JS Jr, King SB 3rd, Jones EL, Craver JM, Bradford JM, Hatcher CR Jr. Reduced efficacy of coronary bypass surgery in women. Circulation 1981;64 (2 Pt 2):П11-6.

52. Bolooki H, Vargas A, Green R, Kaiser GA, Ghahramani $A$. Results of direct coronary artery surgery in women. J Thorac Cardiovasc Surg 1975;69:271-7.

53. Loop FD, Golding LR, MacMillan JP, Cosgrove DM, Lytle BW, Sheldon WC. Coronary artery surgery in women compared with men: analyses of risks and long-term results. J Am Coll Cardiol 1983; 1:383-90.

54. Mensink RP, Katan MB. Effect of a diet enriched with monounsaturated or polyunsaturated fatty acids on levels of low-density and high-density lipoprotein cholesterol in healthy women and men. $\mathrm{N}$ Engl J Med 1989;321:436-41.

55. Garavaglia GE, Messerli FH, Schmieder RE, Nunez $B D$, Oren S. Sex differences in cardiac adaptation to essential hypertension. Eur Heart J 1989;10:1110-4.

56. MRC trial of treatment of mild hypertension: principal results. Medical Research Council Working Party. Br Med J Clin Res Ed 1985;291:97-104.

57. Adami H, Bergstrom R, Holmberg L, Klareskog L, Persson I, Ponten J. The effect of female sex hormones on cancer survival. A register-based study in patients younger than 20 years at diagnosis. JAMA 1990;263:2189-93.

58. Rich-Edwards JW, Manson JE, Hennekens CH, Buring JE. The primary prevention of coronary heart disease in women. $\mathrm{N}$ Engl J Med 1995;332: 1758-66.

59. Walsh JM, Grady D. Treatment of hyperlipidemia in women. JAMA 1995;274:1152-8.

60. Moreno GT, Manson JE. Cholesterol and coronary heart disease in women: an overview of primary and secondary prevention. Coron Artery Dis 1993; 4:580-7.

61. Hamilton VH, Racicot FE, Zowall H, Coupal L, Grover SA. The cost-effectiveness of HMG-CoA reductase inhibitors to prevent coronary heart disease. Estimating the benefits of increasing HDL-C. JAMA 1995;273:1032-38.

62. Johannesson M, Jonsson B, Kjekshus J, Olsson AG, Pedersen TR, Wedel H. Cost effectiveness of simvastatin treatment to lower cholesterol levels in patients with coronary heart disease. Scandinavian Simvastatin Survival Study Group. N Engl J Med
1997;336:332-6.

63. Sempos CT, Cleeman JI, Carroll MD, Johnson CL, Bachorik PS, Gordon DJ, et al. Prevalence of high blood cholesterol among US adults. An update based on guidelines from the second report of the National Cholesterol Education Program Adult Treatment Panel. JAMA 1993;269:3009-14.

64. Pi-Sunyer FX. The fattening of America. JAMA 1994;272:238-9.

65. Kuczmarski RJ, Flegal KM, Campbell SM, Johnson $\mathrm{CL}$. Increasing prevalence of overweight among US adults. The National Health and Nutrition Examination Surveys, 1960 to 1991. JAMA 1994;272:20511.

66. Wysowski DK, Kennedy DL, Gross TP. Prescribed use of cholesterol-lowering drugs in the United States, 1978 through 1988. JAMA 1990;263:2185-8.

67. Palumbo PJ. Cholesterol lowering for all: a closer look. JAMA 1989;262:91-2.

68. Jacobs D, Blackburn H, Higgeins $M$, Reed D, Iso $H$, McMillan G, et al. Report of Conference on Low Blood Cholesterol: mortality associations. Circulation 1992;86:1046-60.

69. Neaton JD, Blackburn H, Jacobs D, Kuller L, Lee DJ, Sherwin R, et al. Serum cholesterol level and mortality findings for men screened in the Multiple Risk Factor Intervention Trial. Arch Intern Med 1992;152:1490-1500.

70. Law MR, Thompson SG, Wald NJ. Assessing possible hazards of reducing serum cholesterol. BMJ 1994;308:373-9.

71. Macdonald LA, Sackett DL, Haynes RB, Taylor DW. Labelling in hypertension: a review of the behavioural and psychological consequences. J Chronic Dis 1984;37:933-42.

72. Cayler GG, Lynn DB, Stein EM. Effect of cardiac "nondisease" on intellectual and perceptual motor development. Br Heart J 1973;35:543-7.

73. Hampton ML, Anderson J, Lavizzo BS, Bergmen AB. Sickle cell "nondisease." A potentially serious public health problem. Am J Dis Child 1974;128:58-61.

74. Morgan RE, Palinkas LA, Barret-Conner EL, Wingard DL. Plasma cholesterol and depressive symptoms in older men. Lancet 1993;341:75-9.

75. Lee JM. Screening and informed consent. N Engl J Med 1993;328:438-40.

76. Sox HC Jr. Preventive health services in adults. $\mathbf{N}$ Engl J Med 1994;330:1589-95. 